Supplement of Atmos. Chem. Phys., 21, 1485-1505, 2021

https://doi.org/10.5194/acp-21-1485-2021-supplement

(C) Author(s) 2021. This work is distributed under

the Creative Commons Attribution 4.0 License.

(c) (1)

Supplement of

\title{
Cold cloud microphysical process rates in a global chemistry-climate model
}

\section{Sara Bacer et al.}

Correspondence to: Sara Bacer (sara.bacer@univ-grenoble-alpes.fr)

The copyright of individual parts of the supplement might differ from the CC BY 4.0 License. 

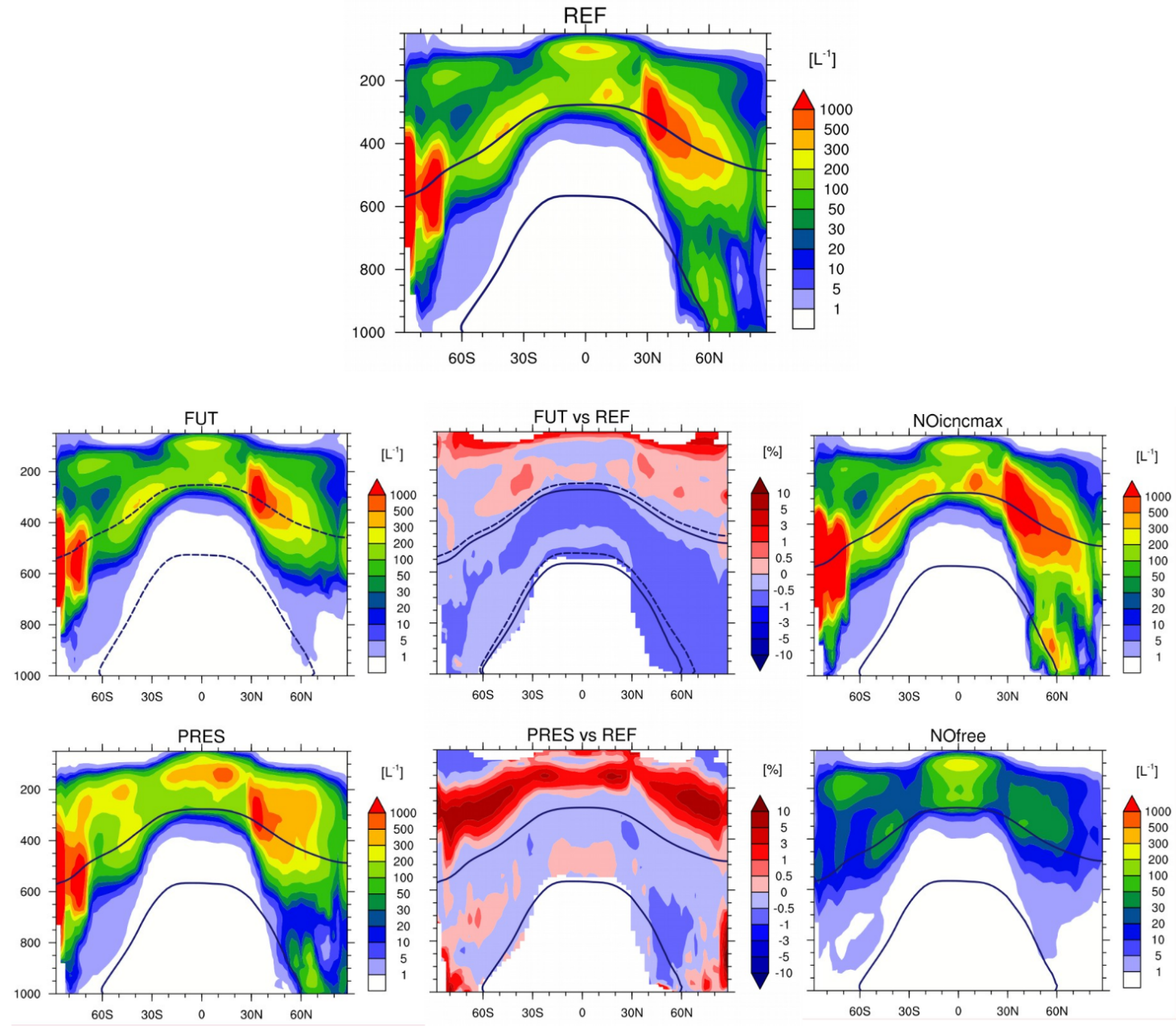

Figure S1. Annual zonal means of (grid-averaged) ICNC for the simulations REF, FUT, and PRES and the test simulations NOicncmax and NOfree. The isotherms at $0^{\circ} \mathrm{C}$ and $-35^{\circ} \mathrm{C}$ are annual means in REF (solid lines) and in FUT (dashed lines). The relative percentage changes are shown where ICNC in REF is $>1 \mathrm{~L}^{-1}$. 


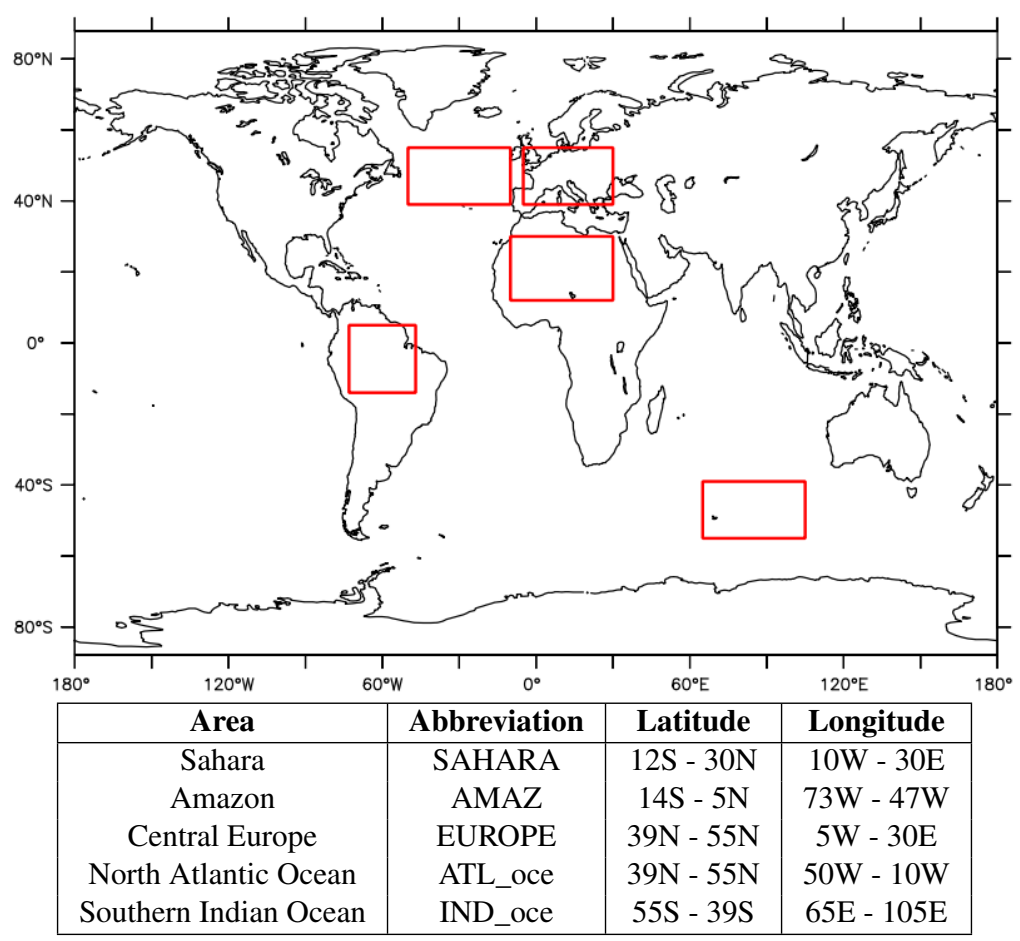

Figure S2. The red rectangles delimit the areas considered for the regional analyses in Section 5.4; the coordinates of the areas are specified in the table.

\begin{tabular}{|c||r|r|r|r|r|}
\hline Tendency & AMAZ & SAHARA & EUROPE & IND_oce & ATL_oce \\
\hline DETR & $5.1 \mathrm{e}+00$ & $1.9 \mathrm{e}+00$ & $2.6 \mathrm{e}+00$ & $2.2 \mathrm{e}+00$ & $1.4 \mathrm{e}+00$ \\
NCIR & $9.8 \mathrm{e}-01$ & $2.1 \mathrm{e}-01$ & $3.2 \mathrm{e}-01$ & $4.5 \mathrm{e}-01$ & $5.1 \mathrm{e}-01$ \\
FREE & $1.7 \mathrm{e}+01$ & $2.7 \mathrm{e}+01$ & $1.2 \mathrm{e}+02$ & $3.1 \mathrm{e}+01$ & $1.9 \mathrm{e}+01$ \\
NMIX & $4.7 \mathrm{e}-03$ & $2.3 \mathrm{e}-01$ & $3.3 \mathrm{e}-01$ & $1.6 \mathrm{e}-01$ & $8.2 \mathrm{e}-02$ \\
SECP & $1.3 \mathrm{e}-02$ & $6.3 \mathrm{e}-03$ & $9.1 \mathrm{e}-02$ & $1.2 \mathrm{e}-01$ & $6.0 \mathrm{e}-02$ \\
\hline MELT & $-2.0 \mathrm{e}-04$ & $-7.7 \mathrm{e}-04$ & $-7.8 \mathrm{e}-03$ & $-1.4 \mathrm{e}-02$ & $-4.9 \mathrm{e}-03$ \\
AGGR & $-5.1 \mathrm{e}+00$ & $-7.8 \mathrm{e}+00$ & $-3.1 \mathrm{e}+01$ & $-1.2 \mathrm{e}+01$ & $-7.9 \mathrm{e}+00$ \\
ACCR & $-2.5 \mathrm{e}+00$ & $-4.2 \mathrm{e}+00$ & $-1.6 \mathrm{e}+01$ & $-5.7 \mathrm{e}+00$ & $-3.9 \mathrm{e}+00$ \\
SELF & $-2.7 \mathrm{e}-02$ & $-4.2 \mathrm{e}-02$ & $-1.8 \mathrm{e}-01$ & $-5.8 \mathrm{e}-02$ & $-3.7 \mathrm{e}-02$ \\
\hline MINMAX+ & $1.2 \mathrm{e}-02$ & $1.1 \mathrm{e}-02$ & $5.1 \mathrm{e}-02$ & $5.1 \mathrm{e}-02$ & $3.3 \mathrm{e}-02$ \\
MINMAX- & $-1.1 \mathrm{e}+01$ & $-1.4 \mathrm{e}+01$ & $-5.9 \mathrm{e}+01$ & $-1.1 \mathrm{e}+01$ & $6.6 \mathrm{e}+00$ \\
\hline
\end{tabular}

Table S1. Mean tendencies (in $\mathrm{m}^{-3} \mathrm{~s}^{-1}$ ) computed over the regions Amazon, Sahara, Central Europe, Southern Indian Ocean, and North Atlantic Ocean. 

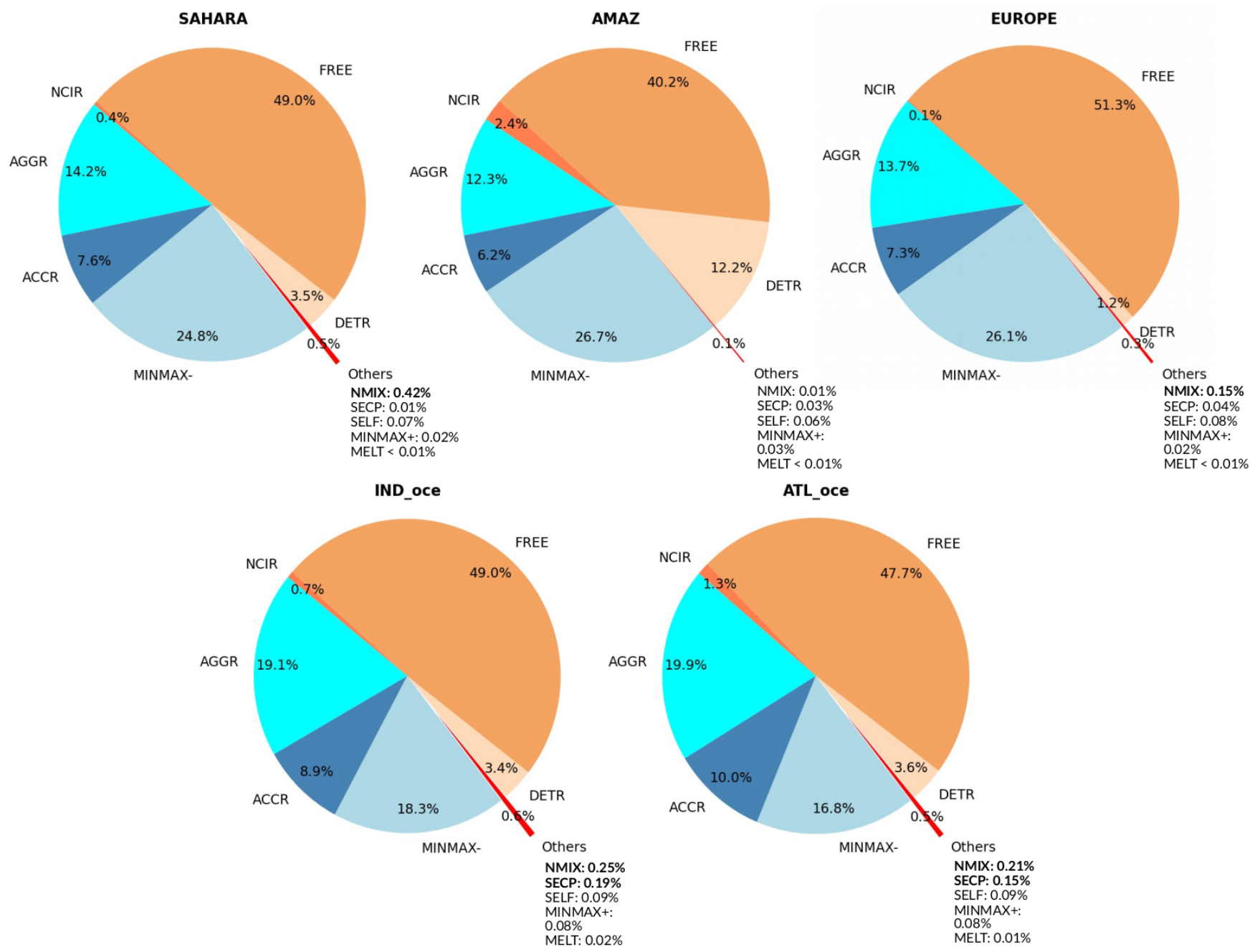

Figure S3. Relative contributions of the mean tendencies in Table S1. The sector "Others" of the pie charts includes NMIX, SECP, MELT, SELF, MINMAX+. Warm tones of colors indicate sources of ICs, while cold tones of colors indicate sinks of ICs. 

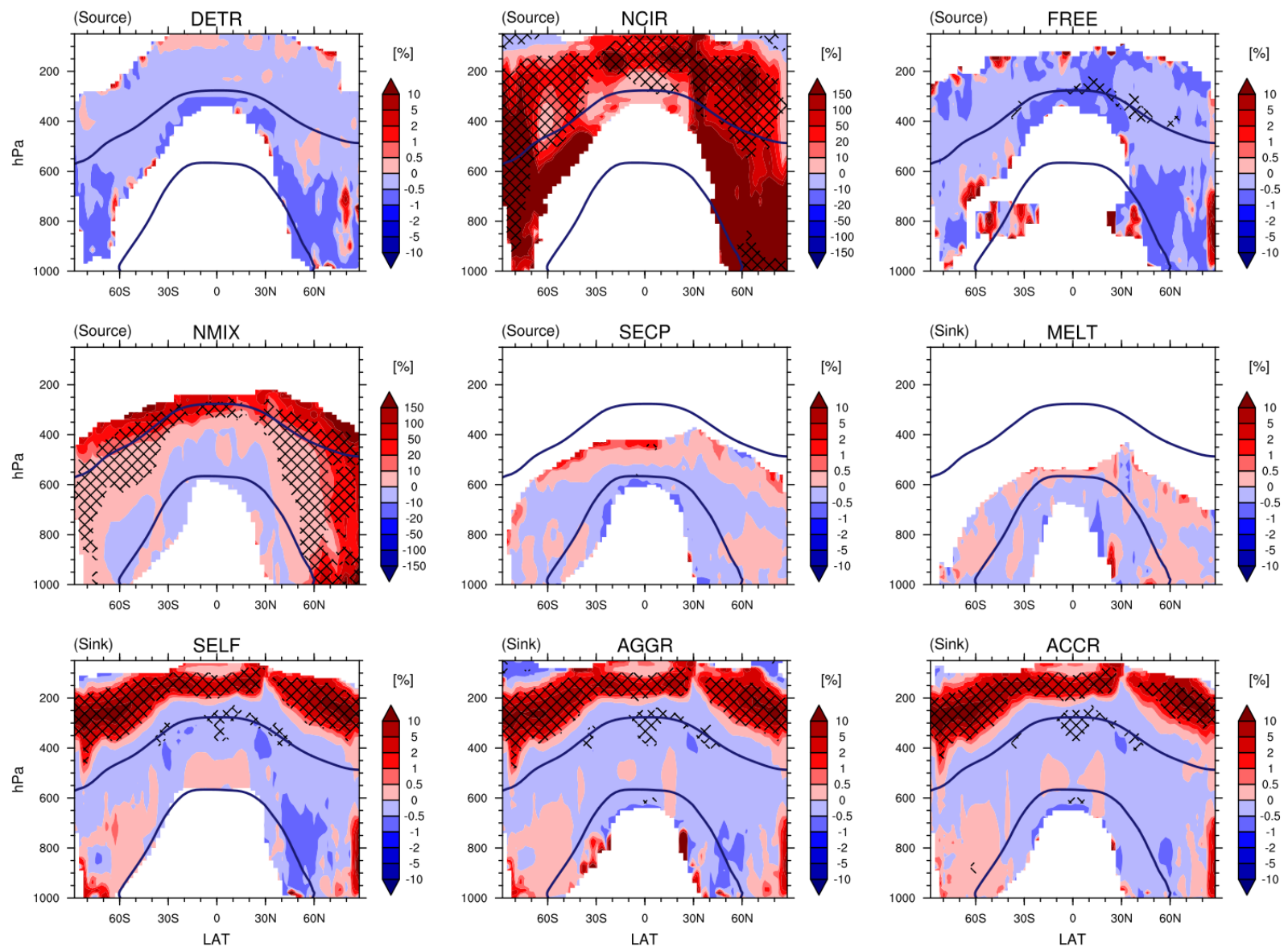

Figure S4. Percentage changes of the tendencies associated to ICNC microphysical processes in cold clouds in PRES with respect to REF. They are computed with daily means and are shown where REF daily means are $>10^{-5} \mathrm{~m}^{-3} \mathrm{~s}^{-1}$. The hatched pattern indicates areas with a significance level of $90 \%$. The isotherms at $0^{\circ} \mathrm{C}$ and $-35^{\circ} \mathrm{C}$ are annual means in REF. 